\title{
Spontaneous closure of a full thickness macular hole
}

\author{
Jasmin Zvorničanin, Edita Zvorničanin, Zlatko Mušanović
}

Department of Ophthalmology, University Clinical Center Tuzla, Tuzla, Bosnia and Herzegovina
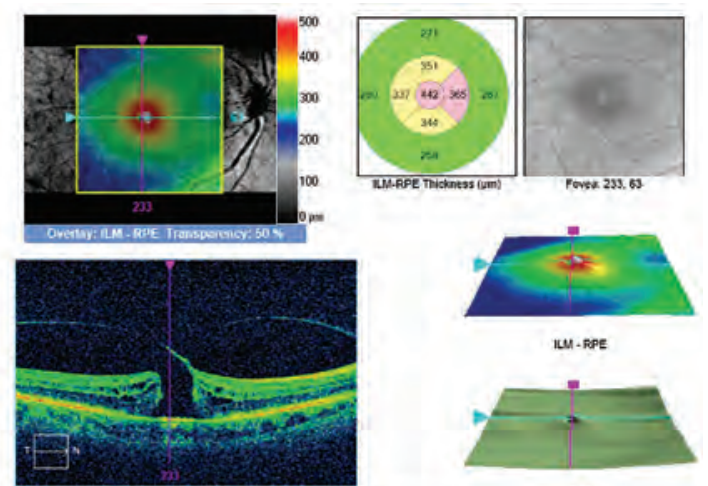

ILA- nop

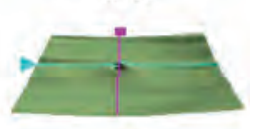

in

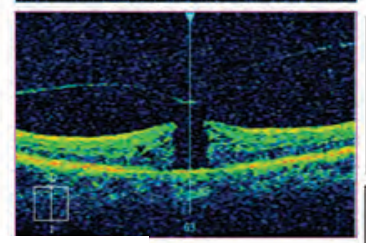

Panel A
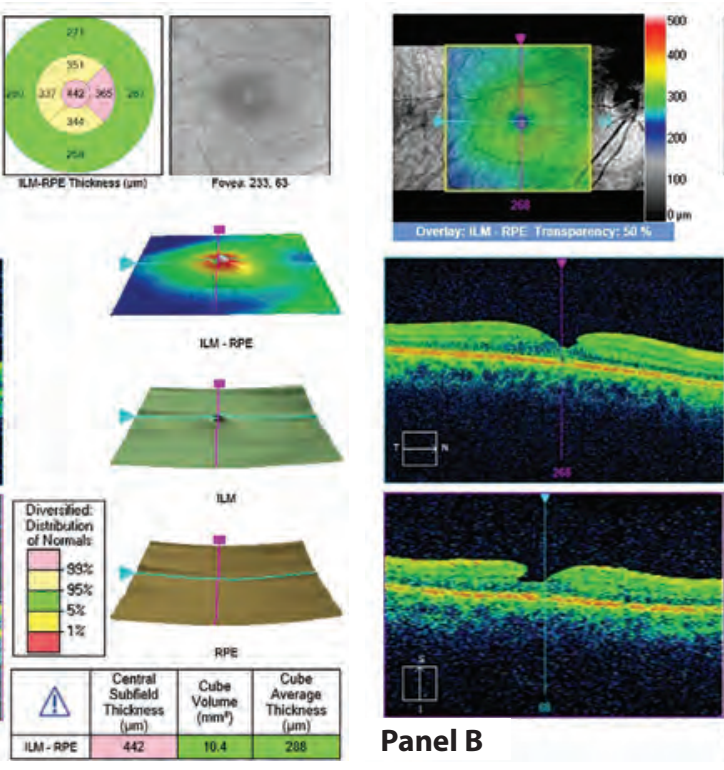

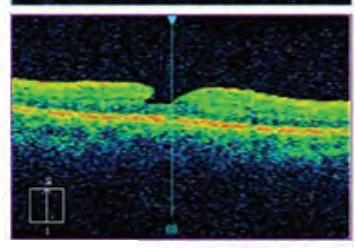

Panel B

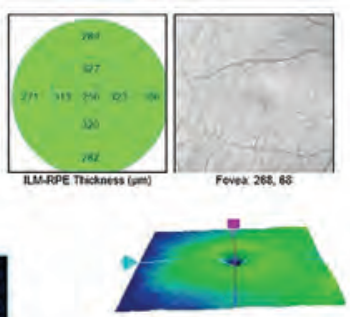

UM-RPE

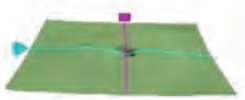

IIM

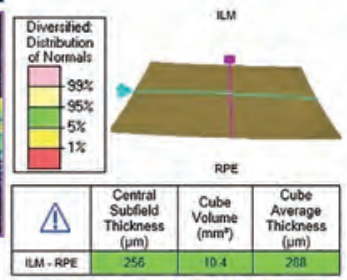

A primary full-thickness macular hole (FTMH) is defined as an idiopathic disruption of all the retinal layers in the fovea (1). Optical coherence tomography (OCT) enables better understanding of various macular disorders, and provides new FTMH classification based on two OCT features: the size, and the presence of vitreomacular traction (VMT) (2). The presence of VMT can be a significant prognostic factor, since FTMH, with the presence of VMT, tends to be smaller in diameter (1). Treatment op-

tions include: observation, pars plana vitrectomy and intravitreal ocriplasmin application $(1,2)$. A 64-year old man was referred with low vision in his right eye, noted five days earlier. Clinical examination revealed visual acuity (VA) of 20/80 in the right eye and 20/20 in the left. Anterior segment examination of both eyes was unremarkable. The measured intraocular pressure was 15 mmHg bilaterally. Fundus examination of the right eye revealed the presence of FTMH, while the left eye was normal. Optical coher- 
ence tomography showed FTMH of $213 \mu \mathrm{m}$ diameter and significant VMT in the right eye, and a normal OCT finding in the left (Panel A). The patient was scheduled for surgical treatment. Fifty-six days after the initial examination, and twelve days before the scheduled surgery, the patient noted significant spontaneous visual improvement. A control examination revealed VA of 20/20 in both eyes. Fundus examination of the right eye presented complete vitreous detachment (PVD) and a small residual foveal depression, while the left eye remained normal. Control OCT examination showed complete spontaneous closure of the FTMH, with a small residual superficial defect and without VMT (Panel B). At the six-month follow up examination, he presented with preserved VA and stable OCT findings. The presence of PVD is reported to be related to the increased size of the FTMH (1). However, a small early FTMH has the capacity to repair itself after complete VMT separation via proliferation of retinal glia cells (2). Spontaneous FTMH closure has previously been reported in up to $3.5 \%$ of cases (3). Therefore, it is important to undertake a detailed preoperative examination in all patients with FTMH, even with persistent VMT.
Key words: Vitreomacular traction syndrome - OCT - Vitreoretinal surgery.

Authors' contributions: Conception and design: JZ and EZ; Acquisition, analysis and interpretation of data: JZ, EZ and ZM; Drafting the article: JZ and EZ; Revising it critically for important intellectual content: JZ and EZ; Approved final version of the manuscript: JZ, EZ and ZM.

Conflict of interest: The authors declare that they have no conflict of interest.

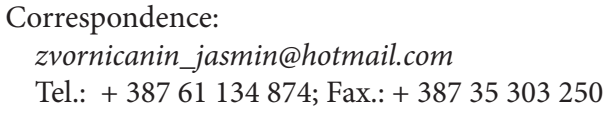

Received: 24 June 2017; Accepted: 1 September 2017

\section{References}

1. Philippakis E, Amouyal F, Couturier A, Boulanger-Scemama E, Gaudric A, Tadayoni R. Size and vitreomacular attachment of primary fullthickness macular holes. Br J Ophthalmol. 2016 Dec 2. pii: bjophthalmol-2016-309212.

2. Steel DH, Lotery AJ. Idiopathic vitreomacular traction and macular hole: a comprehensive review of pathophysiology, diagnosis, and treatment. Eye (Lond). 2013; Suppl 1:S1-21.

3. Sugiyama A, Imasawa M, Chiba T, Iijima H. Reappraisal of Spontaneous Closure Rate of Idiopathic Full-Thickness Macular Holes. Open Ophthalmol J. 2012;6:73-4. 